\title{
LA GERENCIA EN EL DESARROLLO \\ DE LAS EMPRESAS
}

Ladislao Saazedra Rasso

Docente Emérito dela UNMSM.

\section{RESUMEN}

La eficacia de la gestión empresarial es fundamental para que las empresas puedan alcanzar sus metas y objetivos, en otras palabras, para el logro del éxito que esperan.

Si una empresa cuenta con una estructura adecuada y con los recursos necesarios (materiales, humanos y tecnológicos), deben cumplirse las metas y los objetıvos, aunque hay que recordar que siempre se presentan contingencias favorables o adversas de orden interno y externo. Aqu, la gestion empresarial juega un rol muy importante, pues de su eficiencia, producto de la diligencia, habilidades y estrategias que utilicen, dependerá la obtención de buenos resultados.

$\mathrm{Al}$ respecto Meter Drucker, al tratar sobre la efectividad que debe tener todo ejecutivo dice: "La inteligencia, la imagınación y el saber son esenciales, pues únicamente la efectividad los convierte en resultados. De ahí que muchos ejecutivos brillantes, son sorprendentemente ineficaces".

Palabras clave: Gestión empresarial, empresas, gerencia, formación gerencial.

\section{INTRODUCCIÓN}

En los países desarrollados. Se cuida mucho la adecuada utilización de los recursos; y como cuentan con los medios necesarios, tienden a la maximización.

En los países en desarrollo. Se debe procurar la optimización de los limitados recursos y medios con que cuentan.

\section{GERENCIA Y EMPRESAS}

Privadas. Se selecciona a las personas adecuadas y se les exige un gran rendimiento ("Buscar el hombre para el puesto y no el puesto para el hombre").

Públicas. No siempre se cumple lo mencionado en el punto anterior.
Empresas cooperativas. Sin que signifique generalización, que sería injusto, se hace necesario, no perder de vista la gestión gerencial.

Otras empresas e instituciones. Generalmente, se identifica al gerente como el gestor empresarial por excelencia; por lo tanto, se debe cuidar mucho la capacidad y competencia de estos ejecutivos.

\section{CLASES DE GERENTE}

El gerente profesional. Es un ejecutivo profesional, capacitado para movilizar los recursos de las empresas y obtener los mejores resultados. Se espera de él: Una racional toma de decisiones, creatividad y dinamismo. 
Gerencia Familiar. La autoridad real para la toma de decisiones se centra en la familia.

Gerencia Política. Las decisiones más importantessetoman, generalmente, dentro de un "marco político".

\section{CUALIDADES DE UN GERENTE}

- Alto sentido de orientación hacia la eficacia:

a) Fijar prioridades para lo que queremos lograr.

b) Organizar los recursos de una manera eficaz.

- Pro actividad:

- Los gerentes que tienen esta cualidad se encargan $y$ van en todas las oportunidades.

- Son impacientes.

- No pueden esperar hasta que se haga algo.

- Se identifican con lo que hacen.

- Estas personas "quieren resultados".

Cuentan que un racionalizador preguntó en una empresa a una persona: ¿Usted qué hace?; y esta le respondió: "nada"; hizo lo mismo con otra persona y la respuesta fue igual, entonces exclamó: "Hay duplicidad de funciones". Otro ejecutivo gerencial se murió y cuando lo llevaban a enterrar al camposanto en hombros de 6 personas, se levantó del ataúd y dijo: "Por favor, pidan un carrito transportador, así llegamos más rápido y ahorramos 5 personas".

- Velocidad de aprendizaje. Que le permita ser un pensador analítico profundo, que busca experiencias $y$ aprende de la experiencia.

- Dirigencia y liderazgo. Cuando el líder de un grupo tiene mejor educación y mayor experiencia que las personas que están bajo su cargo, estas probablemente trabajarán con mayor entusiasmo. Por lo tanto, podemos decir que:

- La calidad del seguidor determina el nivel del líder.

- Lo primero que debe revisar un gerente es la calidad de la gente que lo sigue.

Se puede graficar lo expuesto con el siguiente ejemplo: $\mathrm{Si}$ en una habitación se juntan 10 idiotas y se cerraran la puerta $y$ las ventanas (que se encontraran sin salida), y uno de ellos dijera: "Yo sé como salir de aquí", los otros lo seguirán. Se ha convertido en un líder, pero sigue siendo idiota.

- Confianza en sí mismo. Debe tener fe y optimismo; aunque el pesimismo en algunos casos resulta positivo.

Así se dice: "Que los optimistas inventaron el avión y los pesimistas inventaron el paracaídas; ambos son indudablemente, útiles".

- Autocontrol. Mantenerse fríos bajo tensión. Esto le per mitirá ver cuatro cosas:

- La dirección correcta,

- la dirección equivocada,

- la mejor forma dehacer loque estamos haciendo, $y$

- cuáles son los peligros que nos esperan.

- Vigor y adaptabilidad:

- Capacidad de poder trabajar muchas horas.

- Adaptación al medio y a la organización que dirige.

- Dicotomía general. La Psicología fisiológica moderna postula una dicotomía del cerebro izquierdo y derecho. Los procesos de razonamiento están primariamente asociados con la 
actividad del lado izquierdo del cerebro. Los procesos intuitivos residen en el lado derecho del cerebro, ya sea a través de influencia hereditaria o del medio ambiente, la gente parece ser más capaz en una de estas esferas que en otras.

Un gerente integrado es uno que se siente igualmente cómodo en ambos aspectos y puede cambiar entre razón e intuición conforme lo demanda la ocasión.

- Capacitación permanente, teórica y práctica

El mundo en el que actuamos es cambiante e incierto, la gerencia es y será un cambio permanente, por lo que un gerente no tendrá éxito sin flexibilidad, agilidad, estudios y "mucha práctica".

Al hablar de incertidumbre, se señala:

- Situaciones conocidas.

- Desconocimiento, que son desconocidos... ni siquiera sospechados.

- Un programa de formación gerencial deberá reconocer estas posibilidades estratégicas, aun si el control es imposible.

- Se requiere una actitud de alerta.

\section{¿POR QUÉ FRACASAN LOS} GERENTES?

- Sentimientos de soledad.

- Deseo de caer bien en lugar de esforzarse por ser respetado: "La mejor manera de fracasar es cuando quieres satisfacer a todos".

- Gerentes con áreas de intereses favoritos.

- Administración por ter ror.

- Nunca hay que trabajen bien.

- Gerentes que ocultan a sus buenos trabajadores.

- Falta de disposición para obligarse a una autovalorización.
LA GERENCIA Y SUS NECESIDADES HUMANAS BÁSICAS

- Ser bien aceptado.

- Que se reconozcan sus méritos propios.

- La seguridad emotiva.

- La seguridad económica.

- necesidad de estudiar en nuestro propio país.

\section{LAS CONDICIONES EN QUE SE DESARROLLA LA ACTIVIDAD GERENCIAL}

- Libertad de acción.

- Apoyo a su gestión

- Colaboración a todos los sectores de la empresa.

\section{EL ROL DEL CONTADOR EN LA GERENCIA}

- Dar a la gerencia lo que ella requiera y no lo que usted cree que necesita. No olvidemos que la gerencia está en mejor posición para conocer todos los problemas de la empresa y la clase de infor mación que necesita.

- Delegar todo lo que se pueda, excepto el control final sobre los resultados y la responsabilidad de ellos. "Mantener el control sobre el resultado de la delegación". A propósito hay dos teorías:

a) Tú consigues lo que inspeccionas, no lo que tú esperas. Es decir, constante control sobre las acciones de los subordinados, delocontrario se pierde el control sobre los resultados.

b) Cuando tu gente está ejercitando autocontrol, no necesitas ejercitar control, porque tienes las cosas bajo control.

Se necesita la capacidad suficiente para escoger buenos colaboradores, capaces y responsables. 
- Establecer y unirse a un balance apropiado entre la conveniencia y la precisión. Los informes contables que se presentan en la gerencia serían ideales si se pudieran condensar en una tarjeta de visita.

- Mejorar la habilidad de comunicación convirtiéndose en un buen oyente. Aquíse deben contemplar dos aspectos:

a) Es imperativo que tú escuches. Algunas frases comunes son: "No tengo tiempo, estoy muy ocupado"; "esto no me concierne, porque no es mi área".

b) El segundo aspecto del problema de escuchar es el proceso automático del cerebro: filtrar.

El proceso cerebral separa lo que no le es familiar y permite percibir solo lo que nosotros deseamos percibir. Por ejemplo, "Esto me interesa; esto no me interesa".

Debemos ampliar nuestra compresión para escuchar lo que la gente está realmente diciendo, captar el mensaje que nos quieren transmitir.
- Mantener y ampliar la habilidad para evitar la obsolescencia tecnológica. Esto significa la actualización permanente, tanto en la especialidad como en conocimientos conexos y también culturales. No existen contadores viejos, ni contadores jóvenes. Solo hay los capaces actualizados y los que no reúnen estas condiciones.

\section{EL ÉXITO PROFESIONAL}

- Económico. Tener altos ingresos económicos: Ganar bien, ¡Qué buena casa!, ¡Qué buen carro!, etc.

- Intelectual Avanzar en los conocimientos o adquirirlos en mayor proporción; cuántos libros hemos leído y qué nuevas experiencias se han logrado.

\section{REFERENCIAS}

1. Drucker, Meter F. Lo esencial de Drucker.

2. Joyse, William; Nahria, Mitin y Bruce Roberson. Lo que realmente funciona.

3. Rojas Fernando. Gestión renovadora. 